\title{
Rising Trend of Nephrectomies in Younger Age Groups
}

Authors

\author{
Deesha Bhemat ${ }^{1}$, Santosh Gawali ${ }^{2}$, Shilpi Sahu ${ }^{3}$, Reeta Dhar ${ }^{4}$ \\ ${ }^{1} 2^{\text {nd }}$ Year Resident, Department of Pathology, MGM Medical College, Kamothe, Navi Mumbai \\ ${ }^{2}$ Assistant Professor, Department of Biochemistry, MGM Medical College, Kamothe, Navi Mumbai \\ ${ }^{3}$ Associate Professor, Department of Pathology, MGM Medical College, Kamothe, Navi Mumbai \\ ${ }^{4}$ Head of Department, Department of Pathology, MGM Medical College, Kamothe, Navi Mumbai \\ Corresponding Author \\ Dr Deesha Bhemat
}

$2^{\text {nd }}$ Year Resident, Pathology Dept, MGM Medical College, Kamothe, Navi Mumbai, Maharashtra, India, Email: deesharamjiyani@gmail.com,Mob-+919173659525

\begin{abstract}
Nephrectomy is common surgery in day-to-day practice of urology. We present a case series of younger patients who underwent nephrectomy between 2014 to Aug'2016 and recorded their details including age, sex, clinical findings, investigations, history regarding the diet, lifestyle and biochemical analysis of calculus. We conclude that in younger age group obstructive nephropathy was the main cause of nephrectomy which resulted in to chronic pyelonephritis.
\end{abstract}

Keywords- Nephrectomy, Younger age group, Urolithiasis, Obstructive Nephropathy, Pyelonephritis.

\section{Introduction}

Nephrectomy is day to day therapeutic urological procedure for benign as well as malignant etiology. In children vesicoureteric reflux and in adult obstructive nephropathy \& malignancy are the leading causes of nephrectomy ${ }^{[1]}$.

In this study we analyse the cause of nephrectomy in young age group ( $<40$ years) with the correlation of clinical data, investigations, dietary history and lifestyle of the patient in an attempt to define the risk factors.

The aim of this article is to explore the existing literature in an effort to identify the potential effects that changes in diet, life-style and obesity have had on the increasing incidence of nephrolithiasis. This in turn may provide a better understanding of the recent trend and what measures may be undertaken for disease prevention.

\section{Materials \& Methods}

During years 2014 to Aug'2016 young patients $(<40$ years), who underwent nephrectomy were included in study. Details including age, sex, clinical findings, investigations, history regarding the diet, lifestyle and biochemical analysis of calculus were recorded (Figure 7). A histopathological report of every patient was reviewed.

\section{Results}

Overall 25 young patients $(<40$ years $)$ were underwent nephrectomy during year 2014 to Aug'2016. Out of which 11 patients with renal stone and 14 patients without renal stone were 
retrospectively reviewed. Based on occupation most of the patients were farmer and fisherman (Figure 1) and having mostly vegetarian and non vegetarian diet (Figure 2). The male to female preponderance was more (M: $\mathrm{F}=3.5: 1)$ and there was slight predominance of right sided lesions. Loin pain was the leading presenting feature in general complaint. The predominant indication for nephrectomy was chronic obstruction culminating in end-stage pyelonephritis, followed upper urinary tract infection. Almost all of the cases with renal stone obstruction had upper urinary tract stones (Figure 4). On biological examination type of stones are commonly calcium oxalate and uric acid groups of stones (Figure 3). In histopathology reports each specimen showed changes of chronic pyelonephritis (Figure 5). 34\% cases of chronic pyelonephritis showed xanthogranulomatous change (Figure 6).

\section{Figure 1}

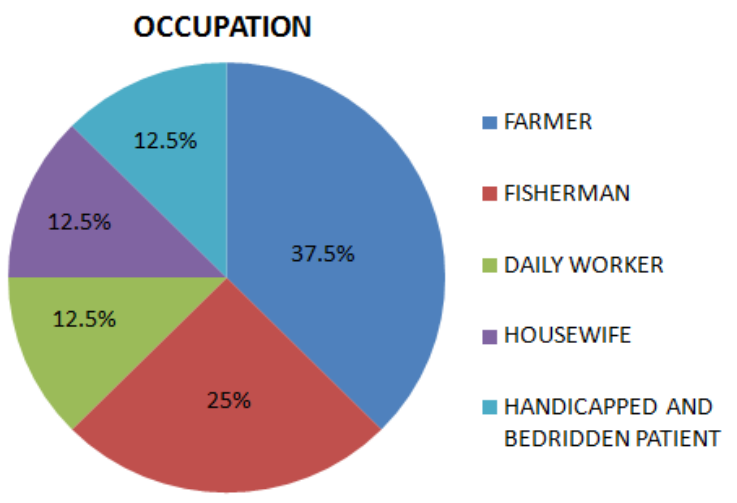

Figure 2

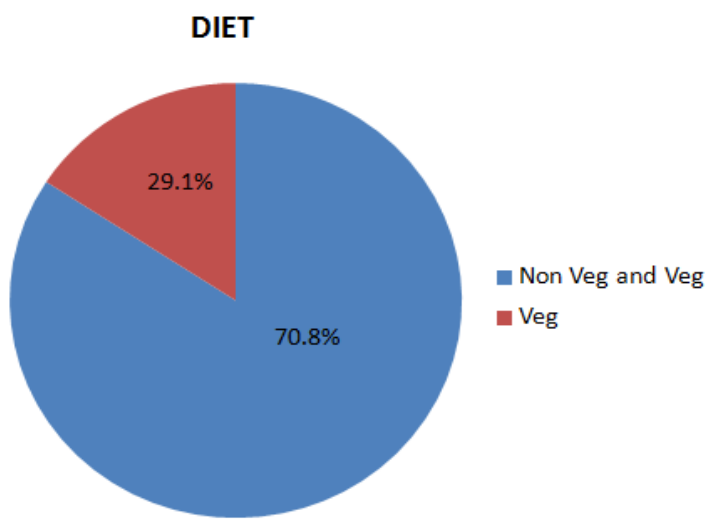

Figure 3

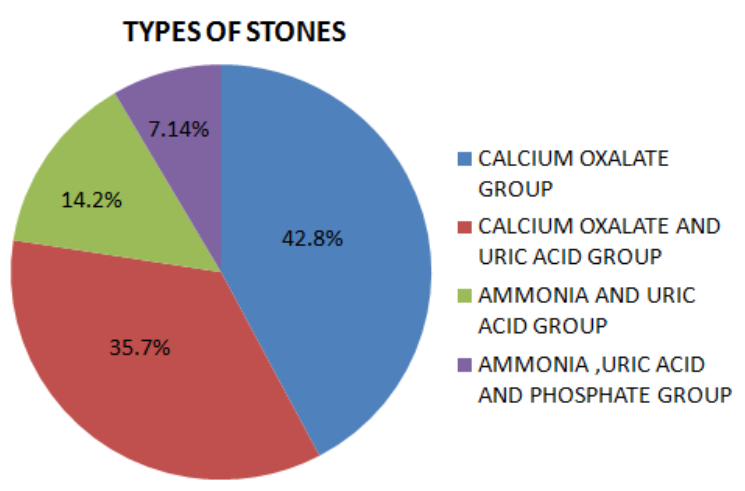

Figure 4: Gross examination

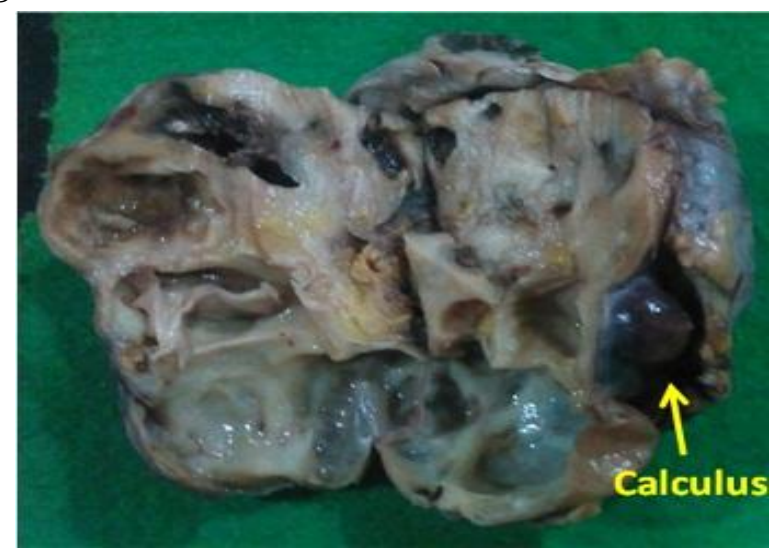

Figure 5: Chronic pyelonephritis showing inflammatory infiltrate.

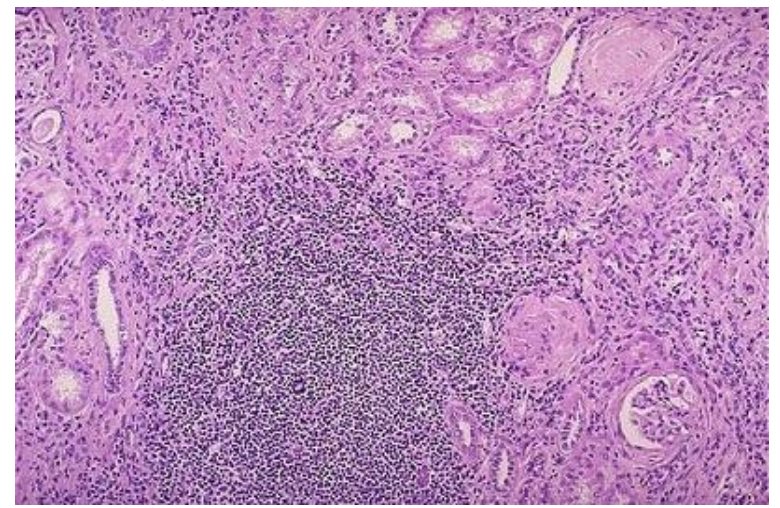

Figure 6: XGP showing granuloma formation

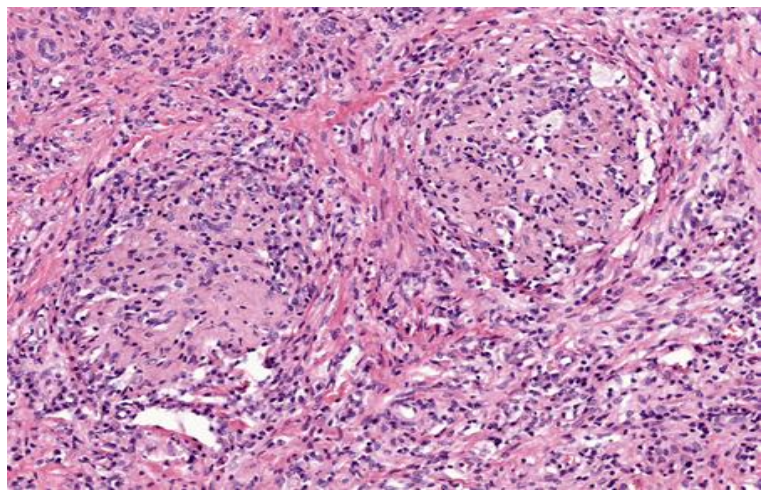


Figure 7

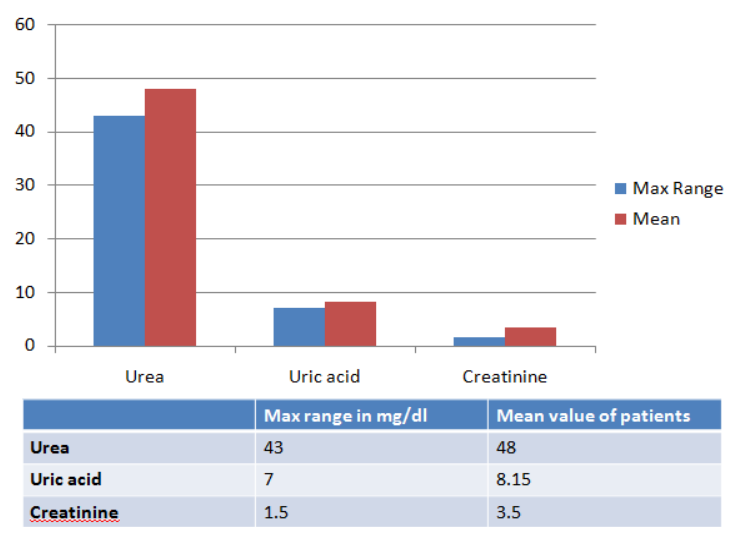

\section{Discussion}

Obstructive uropathy is a common cause of acute and chronic renal failure. In adults, incidence and etiology of urinary obstruction vary significantly with the age and sex of the patient. In young and middle-aged men, renal calculi are the most common cause of at least temporary urinary obstruction ${ }^{[2]}$.

Kidney stones are categorized as either staghorn or non-staghorn. Non-staghorn stones are calyceal or ureteral stones. A majority of kidney stones are calcium stones, with calcium oxalate $(\mathrm{CaOx})$ and calcium phosphate (CaP) accounting for approximately $80 \%$ of all of these stones, uric acid (UA) about $9 \%$, and struvite approximately $10 \%$, leaving only $1 \%$ for all the rest. ${ }^{[3]}$

Curhan et al. sought to examine a relationship between dietary factors and the risk of incident kidney stones. They reported that higher intake of dietary calcium decreased the risk of urinary stone disease in young women, while supplemental calcium did not. ${ }^{[4]}$ Obesity has also been linked to reduction in urinary $\mathrm{pH}$ and associated nephrolithiasis. Najeeb et al. examined the effects of obesity on urinary $\mathrm{pH}$ and urinary stone composition ${ }^{[5]}$ and reported an inverse correlation between patients' BMI and urinary $\mathrm{pH}$. Patients with higher BMI's were found to have lower urinary $\mathrm{pH}$ and higher occurrence rates of urate, calcium oxalate and calcium phosphate stones. Several studies suggest that chronic dehydration from different causes such as working in a hot environment or physical exertion increases the risk of stone incidence. ${ }^{[6]}$ Data suggests also that stone diseases occur more frequently in geographic areas with a hot climate.

Chronic pyelonephritis means chronic inflammation renal parenchyma and pyelocaliceal system, which is almost caused by urinary obstruction or reflux. Gross examination of chronic pyelonephritis reveals thinning of the renal parenchyma of variable degrees, loss of corticomedullary junction landmark, blunting or loss of renal papillae, dilatation of the pyelocaliceal system and thickening of its wall. Microscopic Features of chronic pyelonephritis shows tubular thyroidisation, tubular atrophy, intense diffuse lymphoplasmacytic inflammatory infiltrate with germinal centers, obliterative endarteritis of vessels, interstitial Tamm-Horsfall protein. ${ }^{[7]}$ Granulomatous pyelitis is characterized by granulomatous inflammation limited to the pyelocaliceal wall and without involvement of the renal parenchyma. The granulomatous inflammation characteristically appears as palisading histiocytes/ macrophages along the pyelocaliceal wall, associated with loss of urothelium. ${ }^{[8]}$

Xanthogranulomatous pyelonephritis (XGP) is an uncommon chronic destructive granulomatous process of renal parenchyma in association with long-term urinary tract obstruction and infection. Gross examination of XGP reveals enlarged kidney with hydronephrosis, pelvic calculi (staghorn), or some other chronic obstructive condition. Single or multiple yellow to orange nodules are present, may form a mass and be infiltrative. Microscopic features of XGP is characterized by diffusely or focally replaced renal parenchyma by inflammatory infiltrate which composed of a variable number of xanthomatous histiocytes with foamy cytoplasm, neutrophils, lymphocytes, plasma cells, and multinucleated giant cells. (Figure 6)

\section{Result}

We conclude that obstructive nephropathy was the main cause of nephrectomy which resulted in to chronic pyelonephritis. Urolithiasis was by far the leading pathology associated with obstruction and mainly related to the diet and lifestyle of the patient, 
as discussed most of our patients were farmers in whom inadequate fluid intake was directly linked to stone formation

\section{References}

1. El Malik F, Memon SR, Ibrahim AL, et al. Nephrectomy in Adults: Asir Hospital Experience. Saudi J Kidney Dis Transpl 1997;8: 423-7

2. Michael A Policastro, Urinary Obstruction http://emedicine.medscape.com/article/7784 56-overview

3. Evan AP. Physiopathology and etiology of stone formation in the kidney and the urinary tract. Pediatric Nephrology (Berlin, Germany). 2010;25(5):831-841.

4. Curhan GC, Willett WC, Knight EL, Stampfer MJ. Dietary factors and the risk of incident kidney stones in younger women: Nurses' Health Study II. Arch Intern Med. 2004;164:885-91

5. Najeeb Q, Masood I, Bhaskar N, Kaur H, Singh J, Pandey R, et al. Effect of BMI and urinary $\mathrm{pH}$ on urolithiasis and its composition. Saudi J Kidney Dis Transpl. 2013;24:60-6.

6. Embon OM, Rose GA, Rosenbaum T. Chronic dehydration stone disease. Br J Urol. 1990;66:357-62.

7. Pais VM, Strandhoy JW, Assimos DG. Pathophysiology of urinary tract obstruction. In: Walsh PC, Retik AB, Vaughan ED, et al, eds. Campbell's Urology. 4th ed. Philadelphia, PA: Elsevier; 2007:1195-1226.

8. Gonlusen G, Truong A, Shen SS, et al. Granulomatous pyelitis associated with urinary obstruction: a comprehensive clinicopathologic study. Mod Pathol. 2006;19:1130-1138.

9. Sugie, S., T. Tanaka, A. Nishikawa, et al. Fine-needle aspiration cytology of xanthogranulomatous pyelonephritis. Urology 1991. 37 (4):376-379. 